\title{
A large-scale, multicentre, double-blind trial of ursodeoxycholic acid in patients with chronic hepatitis $C$
}

\author{
Masao Omata, Haruhiko Yoshida, Joji Toyota, Eiichi Tomita, \\ Shuhei Nishiguchi, Norio Hayashi, Shiro lino, Isao Makino, \\ Kiwamu Okita, Gotaro Toda, Kyuichi Tanikawa, \\ Hiromitsu Kumada, for the Japanese C-Viral Hepatitis Network
}

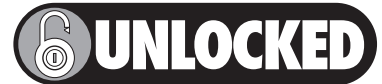

This paper is freely available online under the BMJ Journals unlocked scheme, see http://gut.bmj.com/info/unlocked.dtl
See end of article for authors' affiliations

Correspondence to: Professor Masao Omata, Department of Gastroenterology, University of Tokyo Graduate School of Medicine, Hongo 7-3-1, Bunkyo, Tokyo 113-8655, Japan; omata-2im@

h.u-tokyo.ac.jp

Revised 23 May 2007 Accepted 5 June 2007 Published Online First 20 June 2007
Background: Combined pegylated interferon and ribavirin has improved chronic hepatitis $\mathrm{C}(\mathrm{CH}-\mathrm{C})$ therapy; however, sustained virological response is achieved in only about half of the patients with a $1 \mathrm{lb}$ genotype infection. We assessed oral ursodeoxycholic acid (UDCA) on serum biomarkers as a possible treatment for interferon non-responders.

Methods: $\mathrm{CH}-\mathrm{C}$ patients with elevated alanine aminotransferase (ALT) were assigned randomly to 150 $(n=199), 600(n=200)$ or $900 \mathrm{mg} /$ day $(n=197)$ UDCA intake for 24 weeks. Changes in ALT, aspartate aminotransferase (AST) and gamma-glutamyl transpeptidase (GGT) were assessed. This study is registered at ClinicalTrial.gov, identifier NCT00200343.

Results: ALT, AST and GGT decreased at week 4 and then remained constant during drug administration. The median changes (150, 600 and $900 \mathrm{mg} /$ day, respectively) were: ALT, $-15.3,-29.2$ and $-36.2 \%$; AST, $-13.6,-25.0$ and $-29.8 \%$; GGT, $-22.4,-41.0$ and $-50.0 \%$. These biomarkers decreased significantly less in the $150 \mathrm{mg} /$ day than in the other two groups. Although changes in ALT and AST did not differ between the 600 and $900 \mathrm{mg} /$ day groups, GGT was significantly lower in the $900 \mathrm{mg} /$ day group. In subgroup analysis, ALT decreased significantly in the $900 \mathrm{mg} /$ day group when the baseline GGT exceeded $80 \mathrm{IU} / \mathrm{l}$. Serum HCV-RNA did not change in any group. Adverse effects were reported by $19.1 \%$ of the patients, with no differences between groups.

Conclusions: A $600 \mathrm{mg} /$ day UDCA dose was optimal to decrease ALT and AST levels in CH-C patients. The $900 \mathrm{mg} /$ day dose decreased GGT levels further, and may be preferable in patients with prevailing biliary injuries. for chronic liver disease. In 1994, Takano et al reported a randomised, controlled-dose study of UDCA for $\mathrm{CH}-\mathrm{C}$ : 57 patients were assigned randomly to take 150, 600 or $900 \mathrm{mg} /$ day of UDCA and compared with 17 control patients. ${ }^{9}$ The authors showed that serum levels of alanine aminotransferase

(ALT), aspartate aminotransferase (AST) and gamma-glutamyl transpeptidase (GGT) decreased less with $150 \mathrm{mg} / \mathrm{day}$, the dose recommended by the Japanese national health insurance policy at that time, than with 600 or $900 \mathrm{mg}$ /day, while the results with the latter two doses were similar. Although the effects of UDCA on fibrosis progression rates have not been established, the strong association between serum ALT levels and fibrosis progression rates has been well documented..$^{10}{ }^{11}$ and it can be speculated that a decreased ALT level is associated with delayed fibrosis progression. Thus, the present study was conducted primarily as a dose-finding trial, using the changes in ALT levels as the primary endpoint.

\section{PATIENTS AND METHODS \\ Patients}

Patients with $\mathrm{CH}-\mathrm{C}$ who were 20 years of age or older and tested positive for HCV-RNA or HCV core proteins were recruited as candidates for this study. They were observed for 8 weeks prior to administration of the drug, and those who showed ALT of $61 \mathrm{IU} / \mathrm{l}$ or higher in week -4 were enrolled. Patients were excluded from the study if they had received antiviral treatment (interferon with or without ribavirin) within 20 weeks before the observation period or were treated with corticosteroids, immunosuppressive drugs, glycyrrhizic acid, cholestyramine or other drugs that may affect liver

Abbreviations: ALT, alanine aminotransferase; $A S T$, aspartate aminotransferase; CH-C, chronic hepatitis C; GGT, gamma-glutamyl transpeptidase; $\mathrm{HCV}$, hepatitis $\mathrm{C}$ virus; UDCA, ursodeoxycholic acid 
function or interfere with UDCA metabolism. Patients were also excluded if they: i) had decompensated cirrhosis, viral hepatitis other than hepatitis C, autoimmune liver disease, alcoholic or drug-induced liver injury, malignant tumour, biliary disorder, fulminant hepatitis or peptic ulcer; ii) required hospitalisation for cardiac, renal or pancreatic disease; iii) were pregnant or lactating; iv) alcohol dependent or drinking more than approximately $22 \mathrm{~g}$ /day alcohol; v) were participants in another clinical study within 4 weeks before the observation period; or vi) were sensitive to UDCA or other bile acid preparations.

The protocol was approved by the ethics committee of each institution participating in the study. Patients were informed of the details of the clinical study and agreed to participate. We conducted this clinical study in accordance with the Declaration of Helsinki and good clinical practice.

\section{Study design}

After the 8-week observation period patients were treated with oral (prandial) UDCA (Urso, Mitsubishi Pharma, Osaka, Japan) for 24 weeks at 150, 600 or $900 \mathrm{mg} /$ day, divided into three doses, under double-blind conditions. Double blinding used placebo, 50 and $100 \mathrm{mg}$ tablets identical in appearance to the test drug. The UDCA doses were established from a previous clinical study of UDCA in patients with $\mathrm{CH}-\mathrm{C} .{ }^{9}$ Concomitant use of drugs and therapies included in the exclusion criteria were prohibited throughout the observation and treatment periods.

Changes in serum ALT levels were previously reported to be $-26 \%$ and $-25.5 \%$ with 600 and $900 \mathrm{mg} /$ day of UDCA, respectively, compared to untreated controls and no significant changes were observed with $150 \mathrm{mg} /$ day. ${ }^{9}$ Based on these data, we assumed a standard deviation of $30 \%$ for per cent changes in ALT, and the necessary sample size was calculated to be 200 in each group to detect any superiority of the 600 and $900 \mathrm{mg} /$ day doses over $150 \mathrm{mg} /$ day at a significance level of 0.05 and a power of 0.9 .

We enrolled patients who met all criteria and gave written informed consent between July 2002 and May 2004 in 62 institutions with liver clinics throughout Japan. Each patient was assigned randomly to one of the three dose groups by using numbered containers provided based on a permuted block method (block size: 6).

When treatment or evaluation was discontinued because of patient request, aggravation of symptoms, adverse events or other reasons, prior data were included in the evaluation as final observation data.

To investigate the long-term effects of UDCA, the protocol included an option for additional UDCA administration for a minimum of 28 weeks and a maximum of 80 weeks (total 52104 weeks including the initial 24 weeks) if the ALT level had decreased by at least $15 \%$ at week 20 compared to the baseline. In the additional period, the double-blind setting was discontinued and the dose of $600 \mathrm{mg} /$ day was adopted, which could be increased to $900 \mathrm{mg} /$ day by the decision of each patient and the physician responsible. Patients who entered the additional phase could discontinue UDCA administration anytime after week 52 .

\section{Laboratory tests}

Blood was collected every 4 weeks from the start of the observation period to the end of drug administration. Serum ALT was measured as a primary endpoint of liver function, and AST and GGT as secondary endpoints, using conventional methods. Blood samples taken at the start of observation, at 0 , 4 and 12 weeks of treatment, and at the final observation were analysed to determine leukocyte and erythrocyte counts, haemoglobin, haematocrit, thrombocyte count, and the levels of ALT, AST, GGT, alkaline phosphatase, lactate dehydrogenase, total protein, albumin, cholinesterase, total bilirubin, direct bilirubin, total cholesterol, urea nitrogen, creatinine, Na, K and Cl.

For bile acid composition analysis, blood was collected at the start of treatment and at the final observation in a fasted condition. Serum total bile acid was measured by the $3 \alpha$ hydroxysteroid dehydrogenase method. Bile acid fractions were determined by a specific liquid chromatography-electrospray mass spectrometry, using an HPLC system (Agilent 1100 series, Agilent Technologies, CA, USA) equipped with a C18 cartridge (CAPCELL PAK C18 UG120A, Shiseido, Tokyo, Japan) and a mass spectrometer (Quattro Ultima, Micromass Technologies, Manchester, UK).

Serum HCV-RNA level was measured prior to treatment and at the final observation by a reverse transcriptional polymerasechain-reaction method.

All analyses and measurements were performed in a single contract laboratory (SRL, Tokyo, Japan).

\section{Statistical analysis}

Patients' backgrounds were compared among the three dose groups by $\chi^{2}$ test and ANOVA. Changes in serum ALT, AST and GGT levels due to UDCA administration were compared among the groups by repeated-measure ANOVA. Differences between groups were tested by using linear contrasts. Subgroup analyses of median changes in serum ALT at the final observation, relative to the pre-treatment levels, were performed according to gender, body weight and pre-treatment serum GGT level with Wilcoxon signed-ranks tests. Changes in bile acid and serum HCV-RNA levels were analysed by paired Student's t test. Fischer's exact probability test was applied to the incidences of adverse reactions. A p value $<0.05$ in a twotailed test was considered significant. Analyses were done on the full analysis set. This study is registered at ClinicalTrial.gov, number NCT00200343, and is compliant with the published CONSORT guidelines for performance and publication of clinical trials. ${ }^{12}$

\section{RESULTS \\ Patients}

We enrolled 596 patients; 199 received UDCA at $150 \mathrm{mg}$ /day, 200 at $600 \mathrm{mg} /$ day, and 197 at $900 \mathrm{mg} /$ day. Safety was evaluated in all patients as adverse events based on signs and symptoms and abnormal laboratory test results. Efficacy was evaluated in 586 patients $(195,150 \mathrm{mg} /$ day; 198, $600 \mathrm{mg}$ /day; and 193 at $900 \mathrm{mg} /$ day), excluding 10 who lacked sufficient data. At the end of 24 weeks' administration, 392 patients were eligible for additional long-term administration. Of these patients, 280 chose to participate in the study and others refused mainly because of lack of time. Twenty three patients discontinued before week 52, one of them for biochemical relapse, and other 10 patients violated protocol. The effects of long-term administration were evaluated among the remaining 247 patients (fig 1).

Patients' backgrounds are summarised in table 1. Differences observed in gender, body weight and history of treatment with interferon between the three groups are indicated $(\mathrm{p}<0.15)$.

\section{Changes in ALT, AST and GGT}

Serum ALT, AST and GGT levels before and during treatment are shown in figs 2-4. The responses of ALT, AST and GGT over time were greater for 600 and $900 \mathrm{mg} /$ day administration compared to $150 \mathrm{mg} /$ day (ALT, $\mathrm{p}<0.001$ and $\mathrm{p}=0.02 \mathrm{l}$; AST, $\mathrm{p}<0.001$ and $\mathrm{p}<0.001$; GGT, $\mathrm{p}<0.001$ and $\mathrm{p}<0.001$, respectively). No difference was observed between the 600 and $900 \mathrm{mg} /$ day groups in ALT $(\mathrm{p}=0.926)$ or AST $(\mathrm{p}=0.429)$, but GGT differed significantly $(\mathrm{p}<0.001)$. Serum ALT, AST and 


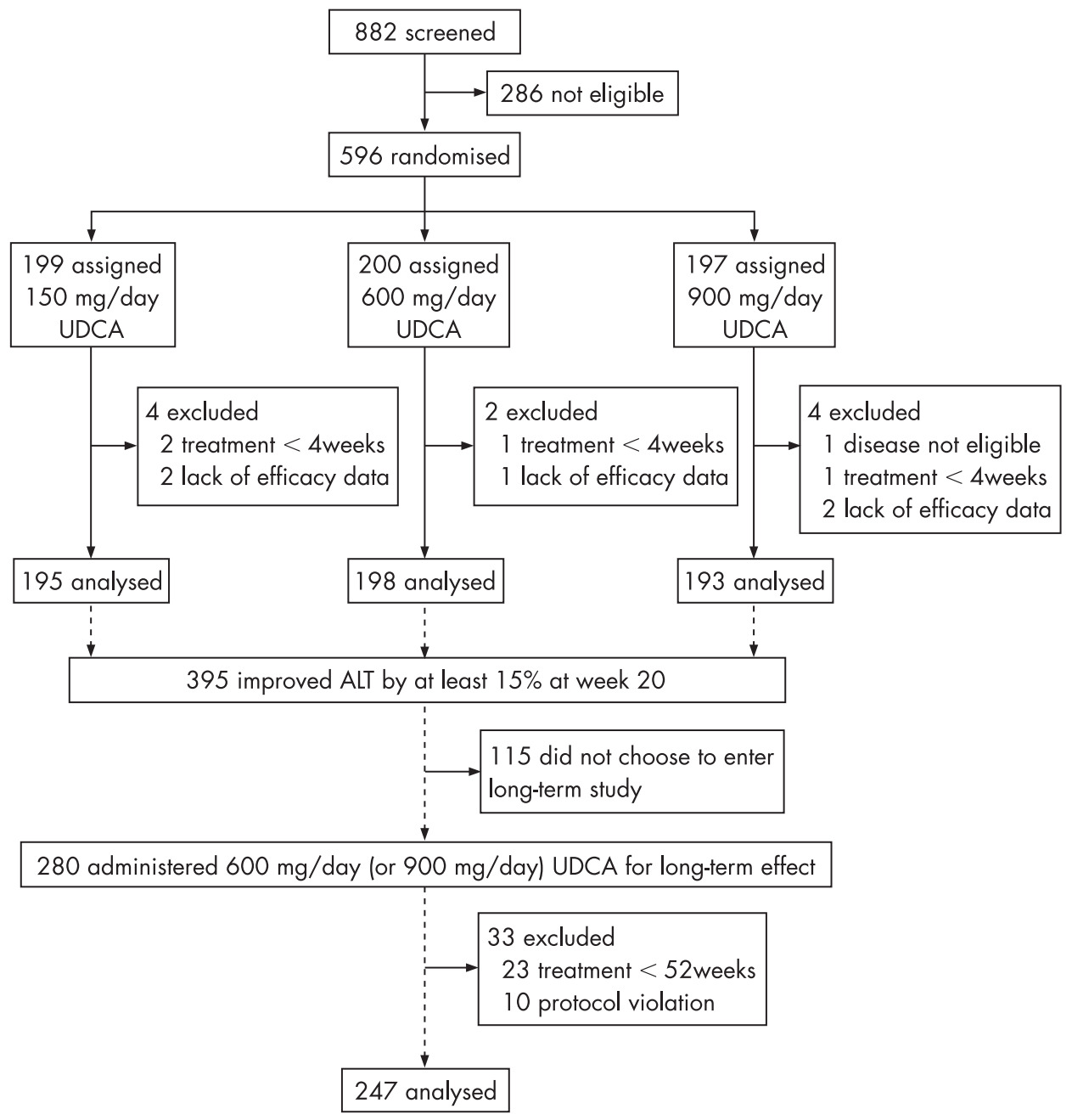

Figure 1 Trial profile.

GGT levels decreased by 4 weeks into treatment and remained constant. Serum ALT, AST and GGT levels at the final observation, together with median changes relative to 0 week (baseline), are shown in table 2. The mean decreases in serum ALT levels from the baseline value were 13.4, 30.6 and 29.3 IU/1 in the 150, 600 and $900 \mathrm{mg} /$ day groups, respectively. The median changes in ALT at the final observation were $-15.3 \%$, $-29.2 \%$ and $-36.2 \%$ in the corresponding groups (table 2 ).

Table 1 Characteristics of patients with chronic hepatitis $C$ treated with UDCA (full analysis set)

\begin{tabular}{|c|c|c|c|c|}
\hline & $\begin{array}{l}150 \mathrm{mg} / \text { day } \\
(\mathrm{n}=195)\end{array}$ & $\begin{array}{l}600 \mathrm{mg} / \text { day } \\
(\mathrm{n}=198)\end{array}$ & $\begin{array}{l}900 \mathrm{mg} / \mathrm{day} \\
(\mathrm{n}=193)\end{array}$ & p Value \\
\hline \multicolumn{5}{|l|}{ Gender } \\
\hline & $97(49$ & 117 (59.1\%) & $123(63.7 \%)$ & 0.018 \\
\hline 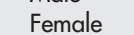 & 9815 & $81(40$ & 70136 & \\
\hline Age (years) & $58.0 \pm 12.2$ & $57.7 \pm 12.0$ & $59.8 \pm 10.1$ & 0.152 \\
\hline & 160. & & & \\
\hline Weight (kg) & $58.8 \pm 11.4$ & $61.8 \pm 11.2$ & $61.6 \pm 11.9$ & 0.017 \\
\hline ALT (IU/I) & $109.2 \pm 49.7$ & $106.3 \pm 59.4$ & $110.6 \pm 57.3$ & 0.745 \\
\hline AST (IU/I) & 84.0 & & & 0.796 \\
\hline GGT (IU/I) & $87.5 \pm 73.0$ & $82.4 \pm 62.2$ & $85.9 \pm 66.3$ & 0.744 \\
\hline \multicolumn{5}{|l|}{ Interferon* } \\
\hline Absent & 119 & 100 & 961 & 0.044 \\
\hline Present & $76(39.0 \%)$ & 98 (49.5\%) & $97(50.3 \%)$ & \\
\hline
\end{tabular}

Data represent the number of patients or mean $\pm S D$. *Previous interferon treatment.
The mean decreases in serum AST levels from the baseline value were $8.5,19.3$ and $19.7 \mathrm{IU} / \mathrm{l}$ in the 150, 600 and $900 \mathrm{mg}$ /day groups, respectively. The mean decreases in serum GGT levels from the baseline value were 17.1, 32.7 and 42.1 IU/1 in the 150, 600 and $900 \mathrm{mg} /$ day groups, respectively.

\section{Long-term effects}

The decreases in ALT, AST, GGT levels from the baseline value were maintained during long-term administration of UDCA, as shown in table 3.

\section{Subgroup analyses}

The decrease in serum ALT was significantly greater in the 600 and $900 \mathrm{mg} /$ day groups than in the $150 \mathrm{mg}$ /day group for most subgroups by gender, body weight or baseline serum GGT levels (table 4). Although the difference between the 600 and $900 \mathrm{mg} /$ day groups as a whole was not significant, the subgroup of baseline GGT $\geqslant 80 \mathrm{IU} / \mathrm{l}$ showed a significantly lower level of GGT with $900 \mathrm{mg} /$ day administration $(\mathrm{p}=0.004)$.

\section{Bile acid in serum}

Total bile acid concentration in serum increased in a dosedependent manner from the start of drug administration to the final observation, as shown in table 5. The ratio of UDCA to total bile acid was increased significantly in all groups at the final observation compared to baseline. The ratio of UDCA at the final observation was similar in the 600 and $900 \mathrm{mg} / \mathrm{day}$ groups. The proportion of less hydrophilic bile acids was 


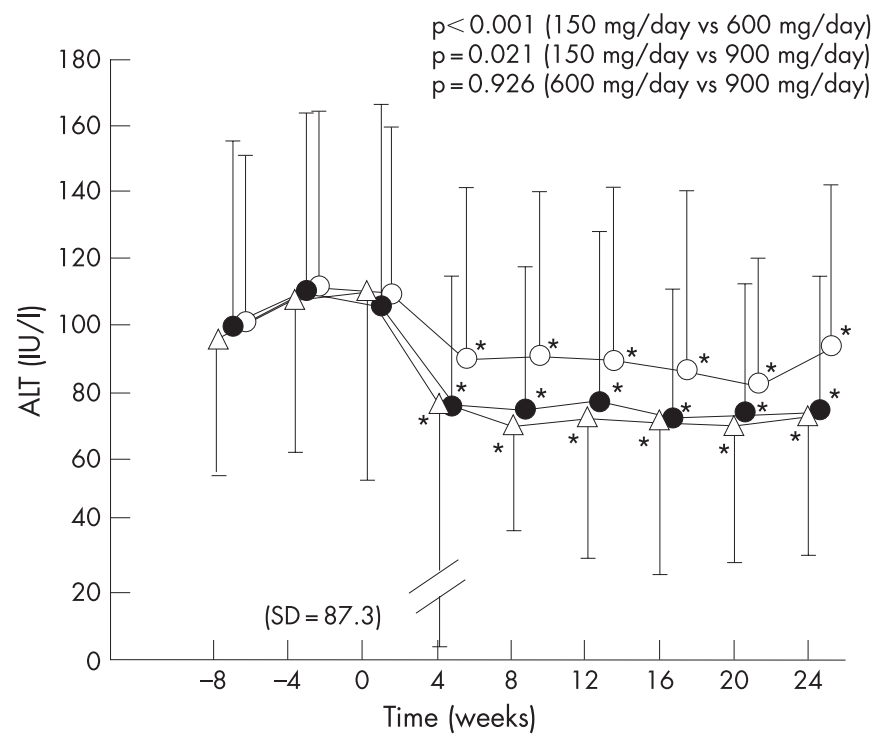

Figure 2 Changes in serum ALT levels in patients with chronic hepatitis C before and during the treatment period. Data are expressed as mean $\pm S D$. Open circles, $150 \mathrm{mg} /$ day; filled circles, $600 \mathrm{mg} /$ day; open triangles, $900 \mathrm{mg} /$ day; ${ }^{*} \mathrm{p}<0.01$, paired t test (vs week 0 ). The $\mathrm{p}$ values refer to repeated measures ANOVA.

decreased accordingly. The proportion of chenodeoxycholic acid at the final observation was decreased significantly in all groups, and was similar in the 600 and $900 \mathrm{mg}$ /day groups. The proportions of cholic acid and deoxycholic acid were also decreased significantly compared to baseline.

\section{Virus load}

HCV-RNA levels (mean \pm SD) changed from the baseline of $1477 \pm 1280$ to $1366 \pm 1224 \mathrm{kIU} / \mathrm{ml}$ in the $150 \mathrm{mg} /$ day group, from $1463 \pm 1299$ to $1358 \pm 1233 \mathrm{kIU} / \mathrm{ml}$ in the $600 \mathrm{mg} / \mathrm{day}$ group, and from $1553 \pm 1318$ to $1552 \pm 1398 \mathrm{kIU} / \mathrm{ml}$ in the $900 \mathrm{mg} /$ day group. None of these changes was significant.

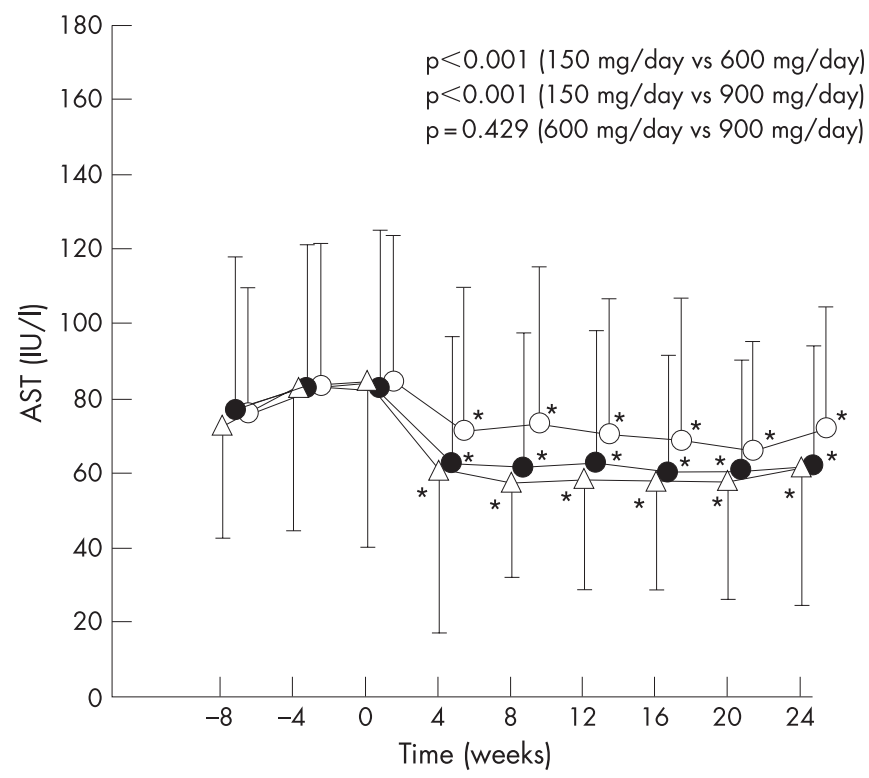

Figure 3 Changes in serum AST levels in patients with chronic hepatitis C before and during the treatment period. Data are expressed as mean \pm SD. Open circles, $150 \mathrm{mg} /$ day; filled circles, $600 \mathrm{mg} /$ day; open triangles, $900 \mathrm{mg} /$ day; ${ }^{*} \mathrm{p}<0.01$, paired $\mathrm{t}$ test (vs week 0$)$. The $\mathrm{p}$ values refer to repeated measures ANOVA.

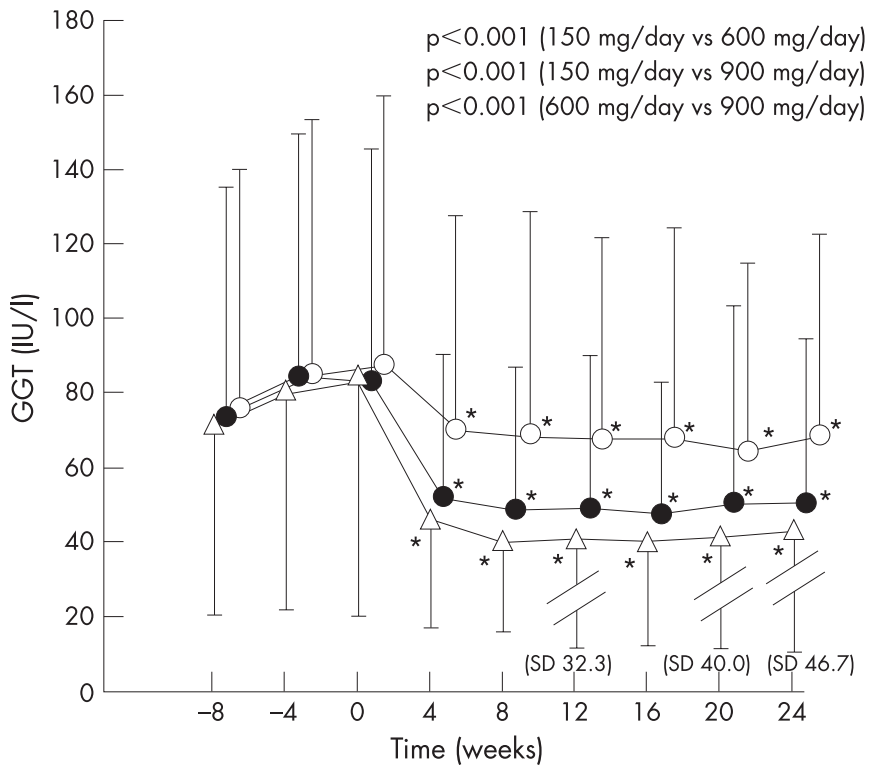

Figure 4 Changes in serum GGT levels in patients with chronic hepatitis $C$ before and during the treatment period. Data are expressed as mean $\pm S D$. Open circles, $150 \mathrm{mg} /$ day; filled circles, $600 \mathrm{mg} /$ day; open triangles, $900 \mathrm{mg} /$ day; ${ }^{*} p<0.01$, paired t test (vs week 0 ). The $p$ values refer to repeated measures ANOVA.

\section{Safety}

The observed adverse reactions possibly associated with UDCA administration are shown in table 6 . The overall incidences of adverse reactions were $18.1 \%, 21.5 \%$ and $17.8 \%$ in the 150,600 and $900 \mathrm{mg} /$ day groups, respectively, with no significant difference between the groups. Diarrhoea was reported most often. No severe adverse reactions were seen.

\section{DISCUSSION}

UDCA is frequently used for cholestatic liver diseases, primary biliary cirrhosis in particular. UDCA improves biochemical indices such as serum GGT, ALT and bilirubin. Histopathological improvements have been $\operatorname{shown}^{13}$ and prolonged survival reported. ${ }^{14}{ }^{15}$ Although its effect on survival remains controversial, ${ }^{16}{ }^{17}$ UDCA is the only approved medication for primary biliary cirrhosis. Suggested mechanisms for UDCA include reducing the cytotoxicity of hydrophobic bile acids, stimulating hepatobiliary secretion and anti-apoptosis. ${ }^{18}$

UDCA was used to decrease serum aminotransferase levels for so-called non-A non-B chronic hepatitis before the discovery of HCV. ${ }^{81920}$ Takano et al restricted their study to patients with $\mathrm{CH}-\mathrm{C}$ and found the optimal dose of UDCA to be $600 \mathrm{mg} /$ day. ${ }^{9}$ There was a greater reduction in GGT (40.5\%) than in ALT $(26.0 \%)$, as also observed in the current study. The reported effect of UDCA was stronger among $\mathrm{CH}-\mathrm{C}$ patients with morphological bile duct injury, ${ }^{21}$ and UDCA administration was accompanied by histological improvement of biliary lesions but not of hepatitis. ${ }^{22}$ These data suggest that UDCA may act on the biliary system in $\mathrm{CH}-\mathrm{C}$ through enhanced bile formation and/or modification of bile acid composition. In fact, bile duct injury is characteristic of $\mathrm{CH}-\mathrm{C}$, although not specific. ${ }^{23}$ In this study, the changes in bile acid composition were similar in the 600 and $900 \mathrm{mg} /$ day groups but smaller in the $150 \mathrm{mg} /$ day group, and this may have been associated with the changes in serum biomarkers.

Nakamura et al reported that UDCA had a greater effect in $\mathrm{CH}-\mathrm{C}$ patients with autoimmune characteristics, that is high immunoglobulin $\mathrm{G}$ concentration or positive anti-nuclear or anti-smooth muscle antibodies, ${ }^{24}$ which suggests involvement 
Table 2 Serum ALT, AST and GGT levels in patients with chronic hepatitis C after treatment with UDCA

\begin{tabular}{lllll}
\hline & Dose (mg/day) & $\begin{array}{l}\text { Pre-treatment, } \\
\text { mean } \pm \text { SD }\end{array}$ & $\begin{array}{l}\text { Post-treatment, } \\
\text { mean } \pm \text { SD }\end{array}$ & $\begin{array}{l}\text { Change (\%), } \\
\text { median (range) }\end{array}$ \\
\hline ALT (IU/I) & 150 & $109.2 \pm 49.7$ & $95.8 \pm 60.2$ & $-15.3(-80.7$ to +375.9$)$ \\
& 600 & $106.3 \pm 59.4$ & $75.7 \pm 41.9$ & $-29.2(-88.3$ to +95.2$)$ \\
AST (IU/I) & 900 & $110.6 \pm 57.3$ & $81.3 \pm 90.5$ & $-36.2(-81.4$ to +1696.9) \\
& 150 & $84.0 \pm 39.1$ & $75.5 \pm 43.6$ & $-13.6(-74.2$ to +347.2$)$ \\
GGT (IU/I) & 600 & $82.4 \pm 41.8$ & $63.1 \pm 32.9$ & $-25.0(-82.7$ to +72.5$)$ \\
& 900 & $85.2 \pm 45.0$ & $65.5 \pm 49.6$ & $-22.4(-79.0$ to +1026.1$)$ \\
& 150 & $87.5 \pm 73.0$ & $70.4 \pm 58.3$ & $-41.0(-81.1$ to +145.9$)$ \\
& 600 & $82.4 \pm 62.2$ & $49.7 \pm 43.0$ & $-50.0(-80.1$ to +213.9$)$ \\
\hline
\end{tabular}

Table 3 Serum ALT, AST and GGT levels in patients with chronic hepatitis $C$ during long-term administration of UDCA

\begin{tabular}{llllll}
\hline & \multicolumn{2}{l}{$\begin{array}{l}\text { Pre- } \\
\text { treatment }\end{array}$} & \multicolumn{2}{l}{ Treatment period } \\
\cline { 2 - 3 } \cline { 5 - 6 } & Week 0 & & Week 24 & Week 48 & Week 104 \\
\hline Patients (n) & 247 & $242^{*}$ & $243 \dagger$ & $149 \pm$ \\
ALT (IU/I) & $114.8 \pm 54.1$ & $70.7 \pm 37.4$ & $67.9 \pm 36.3$ & $63.5 \pm 31.9$ \\
AST (IU/I) & $86.6 \pm 41.7$ & $59.0 \pm 31.5$ & $56.6 \pm 27.4$ & $54.1 \pm 23.7$ \\
GGT (IU/I) & $87.3 \pm 67.6$ & $49.5 \pm 42.6$ & $47.3 \pm 40.5$ & $41.8 \pm 30.1$ \\
\hline
\end{tabular}

Data are expressed as mean \pm SD.

${ }^{*}$ Corresponding data missing in five patients; $†$ corresponding data missing in four patients; ładministration between week 52 and week 104 was optional and 149 patients opted for the maximum term.

of immunomodulatory mechanisms. Indeed, studies in vitro have shown that UDCA suppresses NF- $\mathrm{KB}$-dependent transcription by binding to the glucocorticoid receptor $^{25}$ and decreases proinflammatory cytokine-induced transcription of phospholipase A2. ${ }^{26}$ These mechanisms may act cytoprotectively in vivo. The choleretic and cytoprotective mechanisms are not necessarily mutually exclusive.
We examined the effect of UDCA on $\mathrm{CH}-\mathrm{C}$ in terms of serum biochemical markers in a large-scale, double-blind investigation. We confirmed that a dose of $600 \mathrm{mg} / \mathrm{day}$, that is $10 \mathrm{mg} / \mathrm{kg}$ body weight on average, was more effective than $150 \mathrm{mg} /$ day, while adverse effects remained similar and minimal. The doses of 600 and $900 \mathrm{mg} /$ day induced similar decreases in serum ALT and AST. Consequently, it appears that $600 \mathrm{mg} /$ day is the preferred dose of UDCA, assuming that serum transaminase levels reflect the degree of hepatocellular damage.

The decrease in serum GGT differed significantly between the 600 and $900 \mathrm{mg} /$ day groups. In contrast to the decrease in ALT or AST, that of serum GGT may represent improved cholestasis from biliary injury in $\mathrm{CH}-\mathrm{C}$. Although the importance of biliary injury in $\mathrm{CH}-\mathrm{C}$ is unclear, it is possible that a $900 \mathrm{mg} /$ day dose has additional benefits compared to $600 \mathrm{mg} / \mathrm{day}$, as the incidence of adverse effects did not differ between the two doses. It is of interest that the decrease in ALT was significantly different between the two doses in patients with high baseline GGT levels (table 4).

The long-term effects of UDCA therapy in $\mathrm{CH}$-C patients are yet to be elucidated. Changes in liver histology following UDCA administration are not evident from short-term observation. However, it is possible that delayed progression of fibrosis by UDCA can be revealed only by much longer-term observation,

Table 4 Subgroup analyses of change in serum ALT in patients with chronic hepatitis C after treatment with UDCA

\begin{tabular}{|c|c|c|c|c|c|}
\hline & \multirow[b]{2}{*}{ Dose (mg/ day) } & \multirow[b]{2}{*}{ No. of patients } & \multirow{2}{*}{$\begin{array}{l}\text { Change (\%), } \\
\text { median (range) }\end{array}$} & \multicolumn{2}{|l|}{$p$ Value } \\
\hline & & & & vs $150 \mathrm{mg}$ & vs $600 \mathrm{mg}$ \\
\hline \multicolumn{6}{|l|}{ Gender } \\
\hline \multirow[t]{3}{*}{ Male } & 150 & 97 & $-14.9(-80.7$ to +375.9$)$ & & \\
\hline & 600 & 117 & $-33.1(-88.3$ to +93.1$)$ & $<0.001$ & \\
\hline & 900 & 123 & $-36.4(-79.1$ to +1696.9$)$ & $<0.001$ & 0.430 \\
\hline \multirow[t]{3}{*}{ Female } & 150 & 98 & $-18.0(-79.0$ to +175$)$ & & \\
\hline & 600 & 81 & $-25.0(-74.7$ to +95.2$)$ & 0.058 & \\
\hline & 900 & 70 & $-35.8(-81.4$ to +315.3$)$ & 0.002 & 0.076 \\
\hline \multicolumn{6}{|c|}{ Body weight (kg) } \\
\hline \multirow[t]{3}{*}{$<60$} & 150 & 115 & $-14.9(-80.7$ to +375.9$)$ & & \\
\hline & 600 & 82 & $-28.6(-74.7$ to +95.2$)$ & 0.002 & \\
\hline & 900 & 91 & $-35.2(-81.4$ to +315.3$)$ & 0.001 & 0.356 \\
\hline \multirow[t]{3}{*}{$\geqslant 60$} & 150 & 80 & $-16.7(-73.4$ to +166.1$)$ & & \\
\hline & 600 & 116 & $-30.3(-88.3$ to +93.1$)$ & 0.003 & \\
\hline \multirow{2}{*}{\multicolumn{6}{|c|}{ GGT (IU/I) }} \\
\hline & & & & & \\
\hline \multirow[t]{3}{*}{$\leqslant 39$} & 150 & 45 & $-14.5(-73.4$ to +71.4$)$ & & \\
\hline & 600 & 39 & $-32.7(-62.9$ to +93.1$)$ & 0.049 & \\
\hline & 900 & 45 & $-26.6(-81.4$ to +1696.9$)$ & 0.112 & 0.616 \\
\hline \multirow[t]{3}{*}{$40-79$} & 150 & 79 & $-15.2(-69.1$ to +175$)$ & & \\
\hline & 600 & 90 & $-30.3(-74.7$ to +95.2$)$ & 0.001 & \\
\hline & 900 & 70 & $-36.3(-77.7$ to +200$)$ & $<0.001$ & 0.633 \\
\hline \multirow[t]{3}{*}{$\geqslant 80$} & 150 & 71 & $-18.2(-80.7$ to +375.9$)$ & & \\
\hline & 600 & 69 & $-28.6(-88.3$ to +53.8$)$ & 0.057 & \\
\hline & 900 & 78 & $-41.2(-79.1$ to +119.3$)$ & $<0.001$ & 0.004 \\
\hline
\end{tabular}

The $p$ values refer to Wilcoxon signed-ranks tests. 
Table 5 Composition of serum bile acid in patients with chronic hepatitis $C$ treated with UDCA

\begin{tabular}{|c|c|c|c|c|}
\hline & Dose (mg/day) & Before treatment & After treatment & p Value \\
\hline \multirow[t]{3}{*}{ Total bile acid concentration $(\mu \mathrm{mol} / \mathrm{l})$} & 150 & $8.63 \pm 9.76$ & $13.69 \pm 19.28$ & $<0.001$ \\
\hline & 600 & $9.42 \pm 12.04$ & $21.89 \pm 24.20$ & $<0.001$ \\
\hline & 900 & $9.17 \pm 9.30$ & $28.74 \pm 39.78$ & $<0.001$ \\
\hline \multirow[t]{3}{*}{ Cholic acid (\%) } & 150 & $17.69 \pm 10.33$ & $11.35 \pm 7.08$ & $<0.001$ \\
\hline & 600 & $17.75 \pm 10.35$ & $5.93 \pm 4.53$ & $<0.001$ \\
\hline & 900 & $18.15 \pm 9.54$ & $5.14 \pm 4.19$ & $<0.001$ \\
\hline \multirow[t]{3}{*}{ Deoxycholic acid (\%) } & 150 & $21.62 \pm 16.24$ & $13.84 \pm 11.39$ & $<0.001$ \\
\hline & 600 & $19.86 \pm 16.84$ & $6.50 \pm 7.06$ & $<0.001$ \\
\hline & 900 & $18.74 \pm 15.29$ & $5.68 \pm 6.58$ & $<0.001$ \\
\hline \multirow[t]{3}{*}{ Chenodeoxycholic acid (\%) } & 150 & $54.46 \pm 14.12$ & $39.93 \pm 11.61$ & $<0.001$ \\
\hline & 600 & $55.37 \pm 13.95$ & $24.66 \pm 10.01$ & $<0.001$ \\
\hline & 900 & $55.95 \pm 13.65$ & $23.31 \pm 12.72$ & $<0.001$ \\
\hline \multirow[t]{3}{*}{ Ursodeoxycholic acid (\%) } & 150 & $5.93 \pm 8.72$ & $34.25 \pm 13.75$ & $<0.001$ \\
\hline & 600 & $6.70 \pm 9.72$ & $62.26 \pm 13.69$ & $<0.001$ \\
\hline & 900 & $6.83 \pm 10.6$ & $65.12 \pm 16.84$ & $<0.001$ \\
\hline \multirow{3}{*}{ Lithocholic acid (\%) } & 150 & $0.30 \pm 0.99$ & $0.62 \pm 1.66$ & 0.010 \\
\hline & 600 & $0.33 \pm 1.23$ & $0.66 \pm 1.35$ & 0.010 \\
\hline & 900 & $0.33 \pm 1.12$ & $0.75 \pm 1.49$ & 0.001 \\
\hline
\end{tabular}

Data are expressed as mean $\pm S D$. The $p$ values refer to paired $t$ test (before vs after treatment).

because the natural progression of fibrosis in $\mathrm{CH}-\mathrm{C}$ is usually slow, taking decades to establish cirrhosis. ${ }^{27} 28$ The effect of UDCA lasted for at least 104 weeks without attenuation (table 3).

In the natural course of $\mathrm{CH}-\mathrm{C}$, those patients with normal serum aminotransferase levels show slow fibrosis progression ${ }^{29}$ and a low incidence of hepatocellular carcinoma. $^{3031}$ By multivariate analysis, the risk of hepatocellular carcinoma after interferon treatment without virological response was shown to be $0.26,0.36$ and 0.91 in patients whose ALT levels were normal, moderately elevated (less than twice the upper normal limit) and highly elevated, respectively, compared to untreated patients. It may be that when UDCA lowers serum ALT levels the risk of hepatocellular carcinoma is decreased. A retrospective study showed that hepatocellular carcinoma developed within 5 years from the onset of HCV-related early cirrhosis in 10 of 56 patients (18\%) who took UDCA and 18 of 46 patients (39\%) who did not. ${ }^{32}$ Interestingly, ALT levels were similar in the two groups, possibly because UDCA was likely to be prescribed to those patients with high baseline ALT levels. Although these data were obtained from a non-randomised, retrospective study, they suggest that UDCA may provide cancer protective effects independent of decreasing ALT.

In summary, we confirmed, in a large-scale, double-blind study, that a UDCA dose of $600 \mathrm{mg} /$ day was optimal to decrease serum ALT and AST levels in $\mathrm{CH}-\mathrm{C}$ patients without serious adverse effects. A dose of $900 \mathrm{mg}$ /day resulted in additional

Table 6 Summary of adverse reactions

\begin{tabular}{|c|c|c|c|}
\hline & $\begin{array}{l}150 \\
\mathrm{mg} / \text { day }\end{array}$ & $\begin{array}{l}600 \\
\mathrm{mg} / \text { day }\end{array}$ & $\begin{array}{l}900 \\
\mathrm{mg} / \text { day }\end{array}$ \\
\hline Overall incidence & $\begin{array}{l}18.1 \% \\
(36 / 199)\end{array}$ & $\begin{array}{l}21.5 \% \\
(43 / 200)\end{array}$ & $\begin{array}{l}17.8 \% \\
(35 / 197)\end{array}$ \\
\hline $\begin{array}{l}\text { Total adverse reactions, } \mathrm{n} \\
\text { Common adverse } \\
\text { reactions, } \mathrm{n}(\%)^{*}\end{array}$ & 44 & 62 & 45 \\
\hline Abdominal distension & $2(1.0)$ & $2(1.0)$ & $2(1.0)$ \\
\hline Upper abdominal pain & $2(1.0)$ & $4(2.0)$ & $2(1.0)$ \\
\hline Constipation & $3(1.5)$ & $4(2.0)$ & $2(1.0)$ \\
\hline Diarrhoea & $7(3.5)$ & $8(4.0)$ & $8(4.1)$ \\
\hline Dyspepsia & $3(1.5)$ & $2(1.0)$ & $2(1.0)$ \\
\hline Loose stool & $1(0.5)$ & $6(3.0)$ & $5(2.5)$ \\
\hline Stomach discomfort & $2(1.0)$ & $2(1.0)$ & $3(1.5)$ \\
\hline Pruritus & $3(1.5)$ & $3(1.5)$ & $2(1.0)$ \\
\hline
\end{tabular}

*The adverse reactions which were observed in $1 \%$ or more of the patients. decreases in serum GGT levels, and may be preferred in patients with prevailing biliary injuries. The long-term effects of UDCA administration on prognosis, hepatocarcinogenesis in particular, remain to be investigated in future studies.

\section{ACKNOWLEDGEMENTS}

Investigators who participated in this study are as follows (listed in alphabetical order): Y Aizawa (Jikei University, Aoto Hospital), K Chayama (Hiroshima University), M Daikoku (National Hospital Organization Nagasaki Medical Center), K Dohmen (Okabe Hospital), K Egashira (Sakura Hospital), K Fujimura (Nara Social Insurance Hospital), K Fujise (Jikei University, Kashiwa Hospital), E Harada (National Hospital Organization Tokyo National Hospital), K Hayashi (University of Miyazaki), N Hayashi (Osaka University), K Hino (Delta Clinic), M Hirano (Tokyo Metropolitan Police Hospital), M Honda (Kanazawa University), N Horiike (Ehime University), H Ikematsu (Haradoi Hospital), Y Imai (Ikeda Municipal Hospital), F Imazeki (Chiba University), D Ito (Osaka Saiseikai Nakatsu Hospital), S Kakumu (Aichi Medical University), Y Katano (Nagoya University), M Kato (National Hospital Organization Osaka National Hospital), M Kawaguchi (Okayama Saiseikai General Hospital), T Kawanishi (Inazumi Park Hospital), S Kawata (Yamagata University), Y Kishimoto (San-in Rosai Hospital), M Kudo (Kinki University), H Kumada (Toranomon Hospital), T Kumada (Oogaki Municipal Hospital), M Matsumura (The Institute for Adult Diseases, Asahi Life Foundation), Y Matsuzaki (University of Tsukuba), H Moriwaki (Gifu University), Y Murawaki (Tottori University), I Nakamura (Jichi Medical University, Omiya Medical Center), K Nakamura (Asahikawa Medical College), R Nakata (Japanese Red Cross Medical Center), S Nishiguchi (Osaka City University), S Onishi (Kochi University), Y Osaki (Osaka Red Cross Hospital), H Saito (Keio University), I Sakaida (Yamaguchi University), S Sakisaka (Fukuoka University), Y Sasaki (Kumamoto University), M Sata (Kurume University), A Sato (St. Marianna University, Yokohama City-Seibu Hospital), M Suzuki (St. Marianna University), K Tachi (Kamiiida Hospital), K Tagawa (Mitsui Memorial Hospital), I Takagi (Jikei University, Third Hospital), A Takaki (Okayama University), Y Takei (Juntendo University), E Tanaka (Shinshu University), J Tazawa (Tsuchiura Kyodo General Hospital), K Togawa (Kawasaki Medical University), E Tomita (Gifu Municipal Hospital), J Toyota (Sapporo Kosei General Hospital), A Ueda (Miyazaki Prefectural Miyazaki Hospital), S Watanabe (Akita University), K Yasuda (Kiyokawa Hospital), T Yamanaka (Itabashi Central Hospital), J Yamao (Nara Medical University), H Yoshida (Yame General Hospital), K Yoshioka (Nagoya University), M Zeniya (Jikei University).

Competing interests: Declared (the declaration can be viewed on the Gut website at http://www. gutjnl.com/supplemental). 


\section{Authors' affiliations}

Masao Omata, Haruhiko Yoshida, Department of Gastroenterology, University of Tokyo Graduate School of Medicine, Tokyo, Japan Joji Toyota, Department of Gastroenterology, Sapporo Kosei General Hospital, Hokkaido, Japan

Eiichi Tomita, Department of Gastroenterology, Gifu Municipal Hospital, Gifu, Japan

Shuhei Nishiguchi, Department of Internal Medicine, Hyogo College of Medicine, Hyogo, Japan

Norio Hayashi, Department of Molecular Therapeutics, Osaka University

Graduate School of Medicine, Osaka, Japan

Shiro lino, Seizankai Kiyokawa Hospital, Tokyo, Japan

Isao Makino, Hokushinkai Megumino Hospitals, Hokkaido, Japan

Kiwamu Okita, Social Insurance Shimonoseki Kosei Hospital, Yamaguchi,

Japan

Gotaro Toda, Sempo Tokyo Takanawa Hospital, Tokyo, Japan

Kyuichi Tanikawa, International Institute for Liver Research, Fukuoka, Japan

Hiromitsu Kumada, Department of Gastroenterology, Toranomon

Hospital, Tokyo, Japan

\section{REFERENCES}

1 Wasley A, Alter MJ. Epidemiology of hepatitis C: geographic differences and temporal trends. Semin Liver Dis 2000;20:1-16.

2 El-Serag HB, Davila JA, Petersen NJ, et al. The continuing increase in the incidence of hepatocellular carcinoma in the United States: an update. Ann Intern Med 2003:139:817-23

3 Yoshizawa H. Hepatocellular carcinoma associated with hepatitis $C$ virus infection in Japan: projection to other countries in the foreseeable future. Oncology 2002;62(Suppl 1):8-17.

4 Manns MP, McHutchison JG, Gordon SC, et al. Peginterferon alfa-2b plus ribavirin compared with interferon alfa- $2 b$ plus ribavirin for initial treatment of chronic hepatitis C: a randomised trial. Lancet 2001:358:958-65.

5 Fried MW, Shiffman ML, Reddy KR, et al. Peginterferon alfa-2a plus ribavirin for chronic hepatitis C virus infection. N Engl J Med 2002;347:975-82.

6 Poupon R, Chretien Y, Poupon RE, et al. Is ursodeoxycholic acid an effective treatment for primary biliary cirrhosis? Lancet 1987:1:834-6.

7 Leuschner U, Fischer H, Kurtz W, et al. Ursodeoxycholic acid in primary biliary cirrhosis: results of a controlled double-blind trial. Gastroenterology 1989:97:1268-74

8 Leuschner U, Leuschner M, Sieratzki J, et al. Gallstone dissolution with ursodeoxycholic acid in patients with chronic active hepatitis and two years follow-up. A pilot study. Dig Dis Sci 1985;30:642-9.

9 Takano $\mathrm{S}$, Ito $Y$, Yokosuka O, et al. A multicenter randomized controlled dose study of ursodeoxycholic acid for chronic hepatitis C. Hepatology 1994;20:558-64.

10 Marcellin P, Asselah T, Boyer N. Fibrosis and disease progression in hepatitis C. Hepatology 2002;36:S47-S56.

11 Ghany MG, Kleiner DE, Alter $\mathrm{H}$, et al. Progression of fibrosis in chronic hepatitis C. Gastroenterology 2003;124:97-104.

12 Moher D, Schulz KF, Altman DG, for the CONSORT Group. The CONSORT statement: revised recommendations for improving the quality of reports of parallel-group randomised trials. Lancet 2001;357:1191-4

13 Degott C, Zatrani ES, Callard P, et al. Histopathological study of primary biliary cirrhosis and the effect of ursodeoxycholic acid treatment on histology progression. Hepatology 1999;29:1007-12.
14 Poupon RE, Poupon R, Balkau B, The UDCA-PBC Study Group. Ursodiol for the long-term treatment of primary biliary cirrhosis. N Engl J Med 1994:330:1342-7.

15 Lindor KD, Therneau TM, Jorgensen RA, et al. Effects of ursodeoxycholic acid on survival in patients with primary biliary cirrhosis. Gastroenterology 1996:110:1515-18.

16 Poupon RE, Lindor KD, Cauch-Dudek K, et al. Combined analysis of randomized controlled trials of ursodeoxycholic acid in primary biliary cirrhosis. Gastroenterology 1997;113:884-90.

17 Goulis J, Leandro G, Burroughs AK. Randomised controlled trials of ursodeoxycholic-acid therapy for primary biliary cirrhosis: a meta-analysis. Lancet 1999;354:1053-60.

18 Paumgartner G, Bevers U. Ursodeoxycholic acid in cholestatic liver disease: mechanisms of action and therapeutic use revisited. Hepatology 2002:36:525-31.

19 Osuga T, Tanaka N, Matsuzaki Y, et al. Effect of ursodeoxycholic acid in chronic hepatitis and primary biliary cirrhosis. Dig Dis Sci 1989;34(12 Suppl):49S-51S.

20 Podda M, Ghezzi C, Battezzati PM, et al. Effects of ursodeoxycholic acid and taurine on serum liver enzymes and bile acids in chronic hepatitis. Gastroenterology 1990;98:1044-50.

21 Kiso S, Kawata S, Imai $Y$, et al. Efficacy of ursodeoxycholic acid therapy in chronic viral hepatitis $C$ with high serum gamma-glutamyltranspeptidase levels. J Gastroenterol 1996;31:75-80.

22 Attili AF, Rusticali A, Varriale $M$, et al. The effect of ursodeoxycholic acid on serum enzymes and liver histology in patients with chronic active hepatitis. A 12 month double-blind, placebo-controlled trial. J Hepatol 1994;20:315-20.

23 Goodman ZD, Ishak KG. Histopathology of hepatitis C virus infection. Semin Liver Dis 1995; 15:70-81.

24 Nakamura K, Yoneda M, Takamoto S, et al. Effect of ursodeoxycholic acid on autoimmune-associated chronic hepatitis C. J Gastroenterol Hepatol $1999 ; 14: 413-18$

25 Miura T, Ouchida R, Yoshikawa N, et al. Functional modulation of the glucocorticoid receptor and suppression of NF-kappaB-dependent transcription by ursodeoxycholic acid. J Biol Chem 2001;276:47371-8.

26 Ikegami T, Matsuzaki Y, Fukushima S, et al. Suppressive effect of ursodeoxycholic acid on type IIA phospholipase A2 expression in HepG2 cells. Hepatology 2005;41:896-905.

27 Poynard T, Bedossa P, Opolon P, OBSVIRC, METAVIR, CLINIVIR, and DOSVIRC groups. Natural history of liver fibrosis progression in patients with chronic hepatitis C. Lancet 1997;349:825-32.

28 Shiratori Y, Imazeki F, Moriyama M, et al. Histologic improvement of fibrosis in patients with hepatitis $C$ who have sustained response to interferon therapy. Ann Intern Med 2000;132:517-24

29 Mathurin P, Moussalli J, Cadranel JF, et al. Slow progression rate of fibrosis in hepatitis $\mathrm{C}$ virus patients with persistently normal alanine transaminase activity. Hepatology 1998;27:868-72.

30 Yoshida H, Shiratori Y, Moriyama M, et al. IHIT Study Group. Interferon therapy reduces the risk for hepatocellular carcinoma: national surveillance program of cirrhotic and noncirrhotic patients with chronic hepatitis $C$ in Japan. Inhibition of hepatocarcinogenesis by interferon therapy. Ann Intern Med 1999:131:174-81.

31 Tarao K, Rino Y, Ohkawa S, et al. Sustained low alanine aminotransferase levels can predict the survival for 10 years without hepatocellular carcinoma development in patients with hepatitis $C$ virus-associated liver cirrhosis of child stage A. Intervirology 2004;47:65-71.

32 Tarao K, Fujiyama S, Ohkawa S, et al. Ursodiol use is possibly associated with lower incidence of hepatocellular carcinoma in hepatitis $C$ virus-associated liver cirrhosis. Cancer Epidemiol Biomarkers Prev 2005;14:164-9. 